\title{
Grandmultiparity: Incidence, consequences and outcome in the Niger delta of Nigeria
}

\author{
Azubuike Ikechukwu Joseph ${ }^{1}$, Ibrahim Isa Ayuba ${ }^{2}$, Israel Jeremiah ${ }^{2}$ \\ ${ }^{1}$ Department of Obstetrics and Gynaecology, University of Port Harcourt Teaching Hospital, Port Harcourt, Nigeria \\ ${ }^{2}$ Department of Obstetrics and Gynaecology, College of Health Sciences, Niger Delta University, Amassoma, Nigeria \\ Email: daddayzee@yahoo.com
}

Received 31 March 2013; revised 2 May 2013; accepted 10 May 2013

Copyright (C 2013 Azubuike Ikechukwu Joseph et al. This is an open access article distributed under the Creative Commons Attribution License, which permits unrestricted use, distribution, and reproduction in any medium, provided the original work is properly cited.

\begin{abstract}
Sub-Saharan Africa has the highest rates of maternal and neonatal mortality worldwide. Grandmultiparity has been traditionally considered as a risk factor for adverse pregnancy outcome. The aim of this study is to determine the incidence, neonatal and maternal outcome of pregnancy in grandmultiparous women. This is a retrospective cross sectional study of grandmultiparous patients that were managed at the University of Port Harcourt Teaching Hospital, Rivers State, Nigeria, from $1^{\text {st }}$ April 2007 to $31^{\text {st }}$ March 2009. There were a total of $\mathbf{6 7 6 0}$ deliveries during the study period, out of which 130 were grandmultiparous giving an incidence of $1.92 \%$. Their mean age was 35.99 years and mean parity 5.70 . Most of the patients 62 (47.5\%) were para 5 . About $71(54.5 \%)$ had seconddary education, while $30(22.8 \%)$ had tertiary level of education, 93 (71.3\%) were Booked, while 37 (28.7\%) were unbooked. Hypertension, malaria, antepartum haemorrhage, diabetes mellitus, anaemia and abnormal lie and presentation occurred in 68 (52.6\%) during the Antenatal period with some patients having more than one complication. Labour complications occurred in $25(\mathbf{1 9 . 0 \% )}$ of the patients and 36 (27.4\%) had anaemia at delivery. $80(61.4 \%)$ achieved vaginal delivery. The caesarean section rate was $34.7 \%$, and $74.3 \%$ were performed as emergency procedure. The blood transfusion rate was $12 \%$. The maternal mortality ratio was $1538.46 / 100,000$ live births and the perinatal mortality rate was $107.69 / 1000$ births. It was concluded that the incidence of Grandmultiparity is low in our center compared to other centres in Nigeria, however, they tend to have unfavorable obstetric outcome. Concrete measures must be put in place to address these through specialized antenatal care and adequate management of Un-
\end{abstract}

booked Emergencies.

Keywords: Grandmultiparity; Outcome; Incidence; Niger Delta

\section{INTRODUCTION}

Grandmultiparity can be defined as women who have had 5 or more deliveries after the age of viability which is taken in our environment to be 28 weeks of gestation $[1,2]$. Great-grandmultiparous women are those who are undergoing their tenth or more delivery [3]. Grandmultiparity has traditionally been considered high risk, but recent studies from developed countries have shown that with satisfactory healthcare conditions, grandmultiparity should not be considered dangerous. The risk assessment in this group of patients should be based on the past and present history and not simply on the parity [1,3].

Pregnancy after the fifth delivery is viewed with anxiety, especially by obstetricians in developing countries working with inadequate facilities because of serious consequences to the fetus, the mother, the family and the society in general $[4,5]$. This has led to efforts being made by the non-governmental, national and international agencies to reduce fertility rates.

The incidence varies from place to place with a low incidence in developed countries and a seemingly increasing trend in developing countries [6]. The desire for large families, male child preference, high perinatal and child mortality rates are some of the contributing factors to high parity seen in developing countries [1,2]. Others are high rate of early marriages and divorce as well as non-availability and poor utilization of contraceptive methods [2,7]. Compounding factors are low socioeconomic status, poor female literacy, social deprivation, poor health care infrastructure and delivery system, non-utilization of available antenatal services $[2,7,8]$. 
Several retrospective studies have found increased complication rates, such as gestational hypertension, diabetes, anaemia, multiple pregnancies, abnormal lie and presentation, antepartum haemorrhage, premature labour, prolonged labour, cephalopelvic disproportion, post partum haemorrhage, uterine rupture and increased maternal/perinatal morbidity and mortality [1,7-13].

These complications may be more pronounced in our environment, due to little or no improvement in the socioeconomic status of the populace and lack of facilities for maternal and child health services especially at the primary and secondary levels of Health care. Therefore, a baseline data based on the local population is helpful to ascertain the incidence, maternal and fetal outcome of the grandmultiparae, which are the aims of this study.

\section{METHODOLOGY}

The study is a two year retrospective study of Grandmultiparous pregnancies managed at University of Port Harcourt Teaching Hospital (UPTH), a tertiary hospital in Rivers State, Nigeria from $1^{\text {st }}$ April 2007 to $31^{\text {st }}$ March 2009. Demographic and clinical data were obtained from Antenatal, labour, and neonatal ward records, theater records, patient's records and case notes. The information obtained were coded and transferred onto a proforma already design for the study. Statistical analysis was performed with Statistical Package for Social Sciences (SPSS version 10) where nominal data were compared using the chi square test $(\times 2)$ and the difference between means determined by the students t-test with the level of significance set at $\alpha=0.05$ Ethical Consideration: Approval for this work was given by the Ethical Committee of the UPTH.

\section{RESULTS}

During the period of study, there were 6760 deliveries and 130 cases of grandmultiparae giving an incidence of $1.92 \% .101$ (77.69\%) of the case notes were available for the study and were analyzed.

Table 1 shows the socio-demographic characteristics and booking status of the patients.

The age range of the women was 22 to 48 years with a mean age and standard deviation (SD) of $35.99 \pm 3.86$ years. Their parity ranged from 5 to 10 with a mean parity of $5.70 \pm 0.85$. Great-grandmultiparae accounted for only $1(1.0 \%)$.

Majority of the patients had secondary level of education 71 (54.5\%), while 30 (22.8\%) had tertiary level of education. The parturient were mainly petty traders 63 (48.5\%) and unemployed housewives 36 (27.7\%), while3 (2.0\%) were university students.

The majority were booked patients 93 (71.3\%) while 37 (28.7\%) were unbooked, Pregnancy complications were found in 68 (52.6\%) of the patients and 44 (33.9\%) were Anaemic at Booking (Table 2).

Delivery at term occurred in $92(71.0 \%), 27(21.0 \%)$ had preterm delivery, while $10(8.0 \%)$ of the pregnancies were post term. Labour complications which included hypertension, cephalo-pelvic disproportion, prolonged/ obstructed labour, intrapartum haemorrhage, post partum

Table 1. Socio-demographic characteristics of the patients.

\begin{tabular}{|c|c|c|}
\hline Variable $(\mathrm{n}=101)$ & Number & Percentage \% \\
\hline \multicolumn{3}{|l|}{ Age group (years) } \\
\hline$<30$ & 3 & 2.97 \\
\hline $30-34$ & 30 & 29.70 \\
\hline $35-40$ & 59 & 58.41 \\
\hline$>40$ & 9 & 8.910 \\
\hline \multicolumn{3}{|l|}{ Parity } \\
\hline $5-6$ & 88 & 87.1 \\
\hline $7-8$ & 12 & 11.9 \\
\hline $9-10$ & 1 & 1.0 \\
\hline \multicolumn{3}{|l|}{ Educational status } \\
\hline No formal education & 1 & 1.0 \\
\hline Primary & 22 & 21.8 \\
\hline Secondary & 55 & 54.5 \\
\hline Tertiary & 23 & 22.8 \\
\hline \multicolumn{3}{|l|}{ Occupation } \\
\hline Civil servant & 16 & 15.8 \\
\hline Trader & 49 & 48.5 \\
\hline Housewife & 28 & 27.7 \\
\hline Students & 2 & 2.0 \\
\hline Artisans (seamstress, beauticians, caterer) & 6 & 5.9 \\
\hline \multicolumn{3}{|l|}{ Booking status } \\
\hline Booked & 72 & 71.3 \\
\hline Unbooked & 29 & 28.7 \\
\hline
\end{tabular}

Table 2. Antenatal complications in grandmultiparae.

\begin{tabular}{ccc}
\hline Complication & Frequency & Percentage \% \\
\hline Anaemia & 24 & 14.18 \\
Hypertension & 17 & 10.04 \\
Malaria & 14 & 8.27 \\
Twin pregnancy & 8 & 4.72 \\
Diabetes mellitus & 6 & 3.54 \\
Antepartum haemorrhage & 6 & 3.54 \\
Abnormal lie/presentation & 5 & 2.95 \\
PROM/Preterm labour & 8 & 5.32 \\
Total & 88 & 52.6 \\
\hline
\end{tabular}


haemorrhage and retained placenta were found in 43 (32.8\%) of patients (Table 3). The blood transfusion rate was 16 (12.0\%). There was no case of uterine rupture.

Spontaneous vaginal delivery occurred in 80 (61.4\%), while 45 (34.7\%) had the caesarean section, majority of which were performed as emergencies 33 (74.3\%), (Figure 1). The mean birth weight was $2.96 \mathrm{~kg}$ (Table 4).

There were two maternal deaths from eclampsia and obstructed labour, with maternal mortality ratio of 1538/ 100,000; all were unbooked (100\%). Fifteen perinatal deaths occurred giving a perinatal mortality rate of 115.38/1000 births out of which 13 (85.7\%) occurred in the unbooked patients and the remaining $14.3 \%$ were in the booked.

Table 3. Labour complications in grandmultiparae.

\begin{tabular}{ccc}
\hline Complication & Number & Percentage \\
\hline Hypertension & 10 & 8.6 \\
Cephalopelvic disproportion & 9 & 7.8 \\
Obstructed labour & 6 & 5.2 \\
Post partum haemorrhage & 5 & 4.3 \\
Intrapartum haemorrhage & 3 & 2.6 \\
Prolonged labour & 3 & 2.6 \\
Genital laceration & 1 & 0.9 \\
Retained placenta & 1 & 0.9 \\
Nil & 38 & 32.8 \\
\hline
\end{tabular}

Table 4. Fetal outcome and fetal complication.

\begin{tabular}{ccc}
\hline & Number & Percentage \% \\
\hline Fetal outcome & 86 & 85.2 \\
Delivered alive & 7 & 6.9 \\
Fresh still birth & 7 & 6.9 \\
Macerated still birth & & \\
Early neonatal death & 1 & 1.0 \\
Fetal weight & 3 & 3.0 \\
1000 - 1499 g & 16 & 15.8 \\
1500 - 2499 g & 65 & 65.3 \\
2500 - 3999 g & & \\
$>4000$ g & 16 & 15.9 \\
Indication for “SCBU” admission & 7 & 6.0 \\
Prematurity & 4 & 3.4 \\
Birth asphyxia & 2 & 1.7 \\
Neonatal jaundice & 2 & 1.7 \\
Infant of diabetic mother & 1 & 0.9 \\
Risk of sepsis & 1 & 0.9 \\
Others & &
\end{tabular}

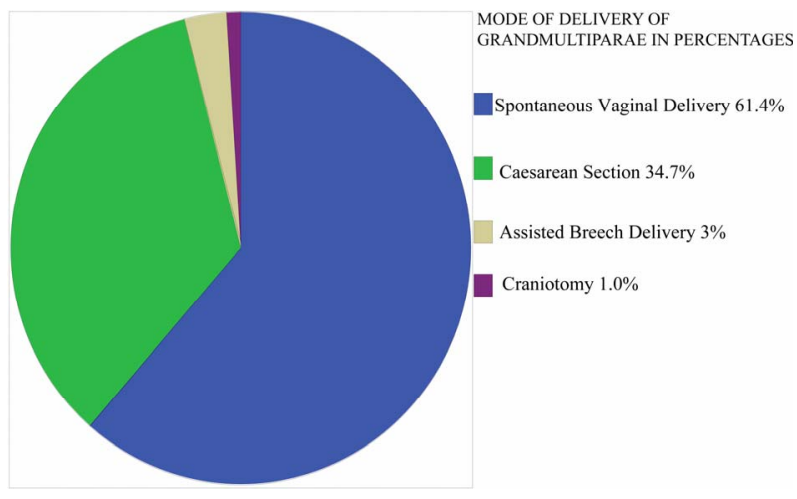

Figure 1. Mode of delivery of grandmultiparae.

\section{DISCUSSION}

The incidence of grandmultiparity in this study was found to be $1.92 \%$. This was lower than was reported in other centres like Lagos, Benin, Enugu and Jos in Nigeria respectively, where the incidence ranged from $4.11 \%$ to $16.4 \%[1,6,12,13]$. This may be attributed to literacy level of the patients; majority of the patients being literate with over $50.0 \%$ with at least a secondary level of education.

The mean age of the grandmultiparae in this study was $35.99 \pm 3.86$ years, this is higher than findings reported from other studies $[1,3,12,13]$. This relatively older age of very high parity mothers may be due to good embrace of western education as reflected in their level of formal education where majority of the patients had secondary and tertiary education.

Majority of the grandmultiparae 4820 (71.3\%) Registered for antenatal care either in the second or third trimester of pregnancy which is in keeping with studies from other centers $[1,6]$.

Anaemia is a common finding in grandmultiparous women and was found in $14.1 \%$ of these patients. The anaemia could be attributable to none replenished iron stores before their index pregnancy [3].

Another common antenatal complication was hypertension and this was also reported from an earlier study in Nigeria [1], this could be due to the increased age found in this group of women; as well as the increased risk of medical complications with increasing age.

Intra-partum complications (32.8\%) reported in this study was higher than what was obtained from other centers $[1,3,14]$, with hypertension and cephalopelvic disproportion being the commonest intrapartum complications. Hypertension was common in booked patient, while obstructed labour was the commonest intrapartum complications in the unbooked grandmultiparae. This is not surprising as mismanaged and neglected labour is commonly found in this group of patients. The finding is similar to that reported in other centres in the country where majority of the patients with obstructed labour 
were unbooked [15-17]. The incidence of post partum haemorrhage was similar to those from Enugu and Ilorin, but lower than those from Jos $[1,11,18]$. Booking status had no relationship with occurrence of post partum haemorrhage in this study. There was no uterine rupture recorded unlike reports from other centers in the country $[1,19]$.

The spontaneous vaginal delivery rate was within the range of $55.35 \%$ to $95.2 \%$, which was similar to earlier reports from other centres in Nigeria $[1,4,19]$.

The caesarean section rate was higher than $14.2 \%$, $14.6 \%$ and $19.9 \%$ reported from South Africa, Jos and Enugu respectively, but was comparable to $30.37 \%$ from Lagos and 36.01\% reported earlier from in our centre [1, 12-14,20], the common indications for caesarean section were malpresentation, cephalopelvic disproportion, severe preeclampsia/eclampsia with an unfavourable cervix and obstructed labour. Most of the patients who had caesarean section were booked, which is in contrast to findings from Lagos where caesarean section was commoner in the unbooked [12].

The incidence of destructive operations was $1 \%$ which was lower than $1.48 \%$ reported from Lagos [12]; this could be attributed to a decline in the art of this procedure amongst practitioners [21].

Majority of the patients delivered at term and the incidence of post term was higher than that reported from South Africa [14]. Macrosomic babies accounted for $16 \%$ of birth weights while low birth weight rate was similar to findings in Ibadan [4]. The significant low birth weight could be from high incidence of twin pregnancy, premature rupture of membrane, preterm labour, intrauterine growth restriction which could occur in patients with hypertensive disorders as well as iatrogenic prematurity from delivery of patients with severe preeclampsia.

Common puerperal morbidities found were; anaemia, hypertension and genital/wound sepsis. These are reflection of complications prevalent during the antenatal and intrapartum period observed in this study.

The maternal mortality ratio reported in the grandmultiparous women from this study was higher than the overall maternal mortality ratio of 1090/100,000 reported in this centre during the period of review [20]. This is also higher than maternal mortality ratio of 1226/100,000 deliveries reported in Jos [13]. The causes of the two maternal deaths recorded were eclampsia and obstructed labour. Unbooked emergencies are known to constitute the main high risk group for maternal mortality in this country as they make up about $70 \%$ of all maternal death [22]. Low socio-economic class, lack of formal education and antenatal care are significant risk factors for maternal deaths and were found in this study.

The perinatal mortality rate was lower than the PNM of 169/1000 reported from Lagos but higher than 73.4/ 1000 from Enugu [1,12]. The identified risk factors from this study are unbooked status, increasing parity, low socio economic status, and illiteracy.

\section{CONCLUSIONS}

This study suggests that grandmultiparous patients need more surveillance during the antenatal period because they are prone to increased incidence of pregnancy and labour complications. Early and safe referral of unbooked grandmultiparae to well manned and equipped centres will help reduce maternal and perinatal morbidities and mortalities.

Improvement in socioeconomic conditions of the populace, health education and widespread practice of family planning are suggested to reduce the incidence of grandmultiparity. More so, utilization of available antenatal services in the tertiary health centre by this group of parturient will effectively reduce the morbidities associated with Grandmultiparity. With adequate care, the maternal and fetal outcome of grandmutiparous women is good and comparable to the multiparous women.

\section{REFERENCES}

[1] Eze, J.N., Okaro, J.M. and Okafor, M.H. (2006) Outcome of pregnancy in the grandmultipara in Enugu, Nigeria. Tropical Journal of Obstetrics and Gynaecology, 23, 811. doi:10.4314/tjog.v23i1.14555

[2] Kuti, O., Dare, F.O. and Ogunniyi, S.O. (2001) Grandmultiparity: Mother's reasons for the index pregnancy. Tropical Journal of Obstetrics and Gynaecology, 18, 3133. doi:10.4314/tjog.v18i1.14447

[3] Bugg, G.J., Atwal, G.S. and Maresh, M. (2002) Grandmultiparae in a modern setting. International Journal of Gynecology \& Obstetrics, 109, 249-253.

[4] Odukogbe, A.A., Adewole, I.F., Ojengbede, O.A., Olayemi, O., Fawole, B.O., Ahmed, Y. and Owoaje, E. (2001) Grandmultiparity-Trends and complications: A study in two hospital settings. Journal of Obstetrics \& Gynaecology, 21, 361-367. doi:10.1080/01443610120059897

[5] Ibekwe, P.C. and Dimejesi, I.B. (2008) Obstetric indices at the Ebonyi State University Teaching Hospital, Abakaliki, South East Nigeria. Nigerian Medical Journal, 17, 399-402. doi:10.4314/njm.v17i4.37420

[6] Gharoro, E.P. and Igbafe, A.A. (2001) Grandmultiparity: Emerging trend in a tropical community. Tropical Journal of Obstetrics and Gynaecology, 18, 27-30. doi:10.4314/tjog.v18i1.14446

[7] Rayamajhi, R., Thapa, M. and Pande, S. (2006) The challenge of grandmultiparity in obstetric population. Kathmandu University Medical Journal (KUMJ), 4, 70-74.

[8] Nassar, A.H., Fayyumy, R., Saab, W., Mehio, G. and Usta, I.M. (2006) Grandmultiparae in modern obstetrics. American Journal of Perinatology, 23, 345-349. 


\section{doi:10.1055/s-2006-947158}

[9] Yasmeen, S., Danielsen, B., Moshesh, M. and Gilbert, W.M. (2005) Is grandmultiparity an independent risk factor for adverse perinatal outcomes? Journal of MaternalFetal and Neonatal Medicine, 17, 277-280. doi:10.1080/14767050500123798

[10] Bukar, M., Audu, B.M., Yahaya, U.R. and Melah, G.S. (2008) Anaemia in pregnancy at booking in Gombe, north-eastern Nigeria. Journal of Obstetrics \& Gynaecology, 8, 775-778. doi:10.1080/01443610802463835

[11] Anorlu, R.I., Oluwole, A.A. and Abudu, O.O. (2006) Sociodemographic factors in anaemia in pregnancy at booking in Lagos, Nigeria. Journal of Obstetrics \& Gynaecology, 26, 773-776. doi:10.1080/01443610600963846

[12] Al-Farsi, Y.M., et al. (2011) Effect of high parity on occurrence of anemia inpregnancy: A cohort study. $B M C$ Pregnancy and Childbirth, 11, 7-15. doi:10.1186/1471-2393-11-7

[13] Fowler-Brown, A.G., et al. (2010) Parity and the association with diabetes in older women. Diabetes Care, 33, 1778-1782.

[14] Ogedengbe, O.K. and Ogunmokun, A.A. (2003) Grandmultiparity in Lagos, Nigeria. Nigerian Postgraduate Medical Journal, 10, 216-219.

[15] Mutihir, J.T. (2005) Obstetric outcome of the grandmultipara in Jos, Nigeria. Tropical Journal of Obstetrics and Gynaecology, 7, 14-20.

[16] Hoque, M., Ehsanul, E. and Kader, S.B. (2008) Pregnancy complications of grandmultiparity at a rural setting of South Africa. Iranian Journal of Reproductive Medicine, 6, 25-31.

[17] Akani, C.I. and Pepple, D.K. (2004) Obstructed labour, barrier and bridges in the Niger delta region of Nigeria. Nigerian Quarterly Journal of Hospital Medicine, 14, 2125.

[18] Omole-Ohonsi, A. and Ashimi, A.O. (2007) Obstructed labour. A six year review in Amino Kano Teaching Hospital, Kano, Nigeria. The Nigerian Medical Practitioner, 51, 59-63. doi:10.4314/nmp.v51i4.28843

[19] Melah, G.S., EL-Nafaty, A.U., Massa, A.A. and Audu, B.M. (2003) Obstructed labour: A public health problem in Gombe, Gombe State, Nigeria. Journal of Obstetrics \& Gynaecology, 23, 369-373. doi:10.1080/01443610310001119510

[20] Ijaiya, M.A., Aboyeji, A.P. and Abubakar, D. (2003) Analysis of 348 consecutive cases of primary post partum haemorrhage at a tertiary hospital in Nigeria. Journal of Obstetrics \& Gynaecology, 23, 374-377. doi:10.1080/0144361031000119529

[21] Ojenuwah, S.A. (2006) Obstetric outcome in grandmultiparae in Bida, North Central Nigeria. Tropical Journal of Obstetrics and Gynaecology, 23, 27-29.

[22] (2007 and 2008) Annual report. Department of Obstetrics and Gynaecology, University of Port Harcourt Teaching Hospital (UPTH), Port Harcourt.

[23] Ezugwu, F.O., Anya, S.E., Onah, H.E. and Okaro, J.M. (2002) Are destructive operations still relevant to obstetric practice in developing countries? Tropical Journal of Obstetrics and Gynaecology, 19, 90-92.

[24] Harrison, K.A. (1995) Poverty, deprivation and maternal health. The 1995 William Meredith Flectcher Shaw memorial lecture. In: Studd, J., Ed., Year Book of the RCOG, Royal College of Obstetrics/Gynaecology, London, 3344. 